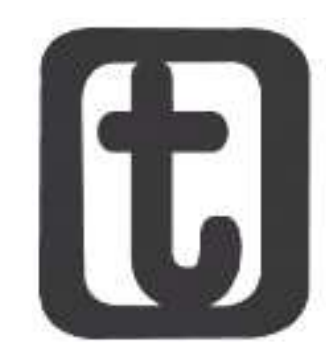

\title{
ASSESSORIA DO SERVIÇO SOCIAL E MOVIMENTOS SOCIAIS INSURGENTES EM DEBATE
}

Social service advisory and insurgent social movements in debate

\author{
Roselene de Souza Portela* \\ https://orcid.org/0000-0003-3339-3528
}

Sandra Helena Ribeiro Cruz**

https://orcid.org/0000-0002-9360-5759

Milcilene Magalhães da Silva***

https://orcid.org/0000-0002-0698-6232

Lidiane Maria Siqueira David****

https://orcid.org/0000-0002-5217-7639

\section{RESUMO}

Este artigo objetiva refletir sobre a prática de assessoria do Serviço Social desenvolvida pelo Programa de Apoio à Reforma Urbana (PARU) junto aos movimentos sociais insurgentes, especificamente a Frente dos Moradores Prejudicados da Bacia Hidrográfica do Una, em Belém do Pará, visando fomentar um espaço político de luta pelo direito à cidade. Evidencia-se a importância da práxis de assessoria junto aos movimentos insurgentes e propõe-se discutir essa correlação com atores sociais pela universidade e pelo Serviço Social. Os procedimentos metodológicos utilizados foram pesquisa bibliográfica e documental sobre a temática da relação de assessoria do Serviço Social e movimentos sociais. Tendo como resultados, os processos que circundam essa relação necessária no cotidiano das lutas e organizações dos movimentos sociais insurgentes, no âmbito do direito à cidade. Dentre os processos evidenciam-se: o processo da relação política; o processo da relação pedagógica; e o processo técnicometodológico.

\section{PALAVRAS-CHAVE}

Assessoria. Serviço Social. Extensão universitária. PARU. FMPBU

\footnotetext{
* Assistente Social. Doutora em Ciências Socioambientais. Docente Adjunto da Faculdade de Serviço Social e do Programa de Pós-Graduação em Serviço Social da Universidade Federal do Pará. Endereço: Rua Augusto Corrêa, 01, Guamá, Belém-Pará, CEP: 66075-110. E-mail: roselene@ufpa.br

** Assistente Social. Doutora. Docente Associada da FASS/PPGSS/UFPA. Rua Augusto Corrêa, 01, Guamá. Belém-Pará, CEP: 66075-110. E-mail: shelena@ufpa.br

*** Assistente Social. Mestranda do Programa de Pós-Graduação em Serviço Social da Universidade Federal do Pará (PPGSS/UFPA). Endereço: Rua Augusto Corrêa, 01, Guamá, Belém-Pará, CEP: 66075-110. E-mail: milci.13@gmail.com **** Assistente Social. Mestranda do Programa de Pós-Graduação em Serviço Social da Universidade Federal do Pará (PPGSS/UFPA). Endereço: Rua Augusto Corrêa, 01, Guamá, Belém-Pará, CEP: 66075-110. E-mail: lididvd@gmail.com
}

DOI 10.22422/temporalis.2020v2on39p192-208 suporte ou formato, bem como adaptar, transformar e criar a partir deste material para qualquer fim, mesmo que comercial. $\mathrm{O}$ licenciante não pode revogar estes direitos desde que você respeite os termos da licença. 


\begin{abstract}
ABSTRAT
This article aims to reflect on the Social Service advisory practice developed by the Urban Reform Support Program (PARU) with the insurgent social movements, specifically the Impaired Residents Front of the Una Hydrographic Basin, in Belém of Pará, in order to foster a political space of fighting for the right to the city.

The importance of the advisory praxis with the insurgent movements is evidenced and it is proposed to discuss this correlation with social actors by the university and the Social Service. The methodological procedures used were bibliographic research and documentary on the theme of the relationship of advisory Social Service to social movements. As a result, the processes that surround this necessary relationship in the daily struggles and organizations of the insurgent social movements, within the scope of the right to the city. Among the processes it is evidenced: the process of the political relation; the process of pedagogical relationship; and the technicalmethodological process.
\end{abstract}

KEYWORDS

Advisory. Social Service. University Extension. PARU. FMPBU

Submetido em: 30/8/2019.

Aceito em: 9/6/2020

\title{
INTRODUÇÃO
}

$\mathrm{N}$

os intempéries que contornam o direito à cidade é que se desdobra o presente artigo, dentro da perspectiva de fazer uma discussão reflexiva sobre a prática de assessoria do Serviço Social desenvolvida pelo Programa de Apoio à Reforma Urbana (PARU), vinculado à Faculdade de Serviço Social, da Universidade Federal do Pará, junto aos movimentos sociais insurgentes, mais especificamente a Frente dos Moradores Prejudicados da Bacia Hidrográfica do Una (FMPBU), tendo como pressupostos de partida para a análise a troca de saberes desenvolvidos e sistematizados por profissionais assistentes sociais, bolsistas do curso de Serviço Social e docentes vinculados ao programa.

Sinaliza-se que, a partir do movimento de reconceituação teórico-metodológica do Serviço Social no Brasil, a profissão trouxe para si o compromisso de elaborar um pensamento social engajado com a reflexão crítica em que as classes trabalhadoras passaram a ser o lugar da intervenção, superando a prática profissional exclusivamente em contexto governamentais. Nessa direção, “[...] este projeto teve como um dos móveis centrais para o seu desenvolvimento, a força política e organizada de um conjunto variado de lutas, movimentos e organizações dos trabalhadores no campo da sociedade civil brasileira" (DURIGUETTO; MARRO, 2016, p. 97).

Em fins de 1970 e durante os anos de 1980, o Serviço Social aproxima-se dos movimentos sociais como espaço de atuação, sendo esta aproximação vinculada "[...] a conjuntura da época [...] marcada pela imersão dos movimentos sociais vinculados à questão do cotidiano, na luta por melhores condições de vida" (MATOS, 2010, p. 40). Naquele período há emersão de inúmeras mobilizações em prol do direito à habitação, saneamento, saúde, ensino e entre outros.

Em 1980, o curso de Serviço Social, da Universidade Federal do Pará (UFPA), adotou como campo de atuação as organizações comunitárias dos bairros periféricos de Belém, capital do estado do Pará, especialmente aqueles circunscritos à própria UFPA, como Guamá e Terra Firme, contribuindo com o trabalho de assessoria aos movimentos sociais que emergiam naquela época.

O Serviço Social passou a contribuir com o trabalho de assessoria aos movimentos sociais, acompanhando os processos de mobilização e organização; elaborando documentos e dossiês de forma a subsidiar especialmente a luta pelo direito à moradia e saneamento.

Temporalis, Brasília (DF), ano 20, n. 39, p. 191-208, jan./jun. 2020. | ISSN 2238-1856 
No período de 1992 a 1993, configuram-se a materialização do Programa de Apoio à Reforma Urbana (PARU), vinculado a Faculdade de Serviço Social, que demandava, além da atuação profissional do Serviço Social, a implementação de campos de estágio, com disciplina e cargas horárias para os docentes desenvolverem suas atividades de ensino e de extensão, como também direcionar uma intervenção mais sistemática da universidade junto aos segmentos organizados da sociedade civil.

Recentemente, o PARU, por meio do desenvolvimento de pesquisas sociais, busca analisar a questão urbana na Amazônia à luz de grandes projetos de intervenção urbanística, cujos resultados são socializados aos movimentos das áreas impactadas, subsidiando a luta social na região, visando potencializar e articular os resultados dessas pesquisas com as ações de extensão, por meio da assessoria e capacitação de lideranças dos movimentos sociais urbanos em Belém, integrando a pesquisa e a extensão e, ainda, dando ênfase ao papel da universidade de produzir conhecimento à sociedade.

As atividades realizadas pelo programa, especialmente as práticas de assessoria do Serviço Social, contribuem para o conhecimento da realidade urbana em Belém, tornando possível verificar os níveis de desigualdades sociais geradas por intervenções urbanísticas, que produz o deslocamento compulsório de populações atingidas; a permanente retificação de igarapés como solução de saneamento, cujos aspectos geram conflitos motivadores da organização de movimentos sociais no contexto das bacias hidrográficas em defesa da moradia, do trabalho, do meio ambiente urbano e da vida urbana como elementos definidores do direito à cidade, tornando fundamental a construção de alternativas coletivas em defesa da vida urbana nas bacias hidrográficas, que se materializam pela emersão de movimentos insurgentes.

Um dos maiores desafios para os setores organizados e consciente de dimensão e da complexidade das coisas objetivas da sociedade capitalista na atualidade é a criação e sustentação de mecanismos de resistência e de luta (LOPES, 2012). Nesse contexto, "[...] o direito à cidade não é apenas um direito condicionado de acesso aquilo que já existe, mas sim um direito ativo de fazer a cidade diferente [...] de acordo com nossas necessidades" (HARVEY, 2013, p. 33).

A organização e fortalecimento dos movimentos populares são formas de resistência e mecanismo de ação na garantia do direito à cidade, conforme sinaliza Harvey (2013, p. 33), "[...] o direito à cidade não é um presente. Ele tem que ser tomado pelo movimento político".

Dessa maneira, a vida urbana tem se direcionado para uma plataforma de reivindicações pelo acesso à moradia digna. Frisa-se que na discussão aqui apresentada o método crítico dialético é o aporte que permite adentrar na realidade dos fenômenos sociais, apreendendo suas determinações particulares, e fazer a relação com o que é geral, possibilitando, assim, compreender o objeto/fenômeno social na sua totalidade, ou seja, "[...] o conhecimento concreto do objeto é o conhecimento das suas múltiplas determinações [...]", segundo Netto (2011, p. 45).

Nesta direção, sinaliza-se a técnica investigativa qualitativa, pois tem a importância de se trabalhar com a complexidade, a especificidade e diferenciações internas para, assim, serem contextualizadas e tratadas dentro de sua particularidade, como ressalta Minayo (2009), "[...] a

Temporalis, Brasília (DF), ano 20, n. 39, p. 191-208, jan./jun. 2020. | ISSN 2238-1856 
importância de trabalhar com a complexidade e as diferenciações internas dos nossos objetos de pesquisa que precisam ser, ao mesmo tempo, contextualizadas e tratadas em sua singularidade" (MINAYO, 2009, p. 25).

Diante disso, metodologicamente, o trabalho centra-se em levantamento bibliográfico e documental, pautando-se no relato de experiência da prática de assessoria do Serviço Social desenvolvido pelo PARU junto aos movimentos sociais insurgentes, especificamente a Frente dos Moradores Prejudicados da Bacia Hidrográfica do Una, em Belém. Portanto, destaca-se que tais ações culminaram em duas pesquisas de Trabalho de Conclusão de Curso voltadas à temática: Assessoria e Extensão Universitária: uma reflexão sobre a prática desenvolvida pelo Programa de Apoio à Reforma Urbana no período de 2014 a 2016, e Assessoria, Serviço Social e Movimentos Sociais Urbanos: a experiência da Frente de Defesa das Bacias de Belém no Programa de Apoio à Reforma Urbana, em 2017.

E, além destes, ressaltam-se três planos de trabalho executados com os seguintes títulos: $\mathrm{Da}$ Assessoria à Formação Política aos Movimentos Sociais Populares Urbanos: Luta Social, Política Urbana e Direito à Cidade; Serviço Social e a Prática da Assessoria aos Movimentos Sociais Urbanos de Belém, em 2017; e Serviço Social e a Prática da Assessoria aos Movimentos Sociais Urbanos em Belém: as Frentes dos Prejudicados do Una e Tucunduba, a Associação de Moradores da Orla da Estrada Nova, a Frente de Defesa das Bacias de Belém e o Comitê Popular Urbano, em 2018.

Dentro desses estudos, evidenciam-se processos que circundam a relação necessária do cotidiano das lutas e organizações dos movimentos sociais insurgentes, no âmbito do direito à cidade no contexto da sociedade capitalista contraditório, desigual e classista. Dentre os processos destacam-se: o processo da relação política, o processo da relação pedagógica, o processo técnico-metodológico, e processo que envolve a questão da tutela.

\section{CONTEXTUALIZAÇÃO DA ASSESSORIA DO SERVIÇO SOCIAL AOS MOVIMENTOS SOCIAIS: BREVE HISTÓRICO}

A prática de assessoria aos movimentos populares tem suas primeiras aproximações sobre a emergência de situar o trabalho com e para as classes subalternas, que nasce envolvido em executar ações amenizadoras e atenuadoras das mazelas da época e principalmente referente às condições de trabalho na década 1930 do século XX, que perpassam para o século XXI, desdobrando novas requisições, novas posturas, para esta prática ainda difusa e pouco exercida nos espaços sócio ocupacionais, como a assessoria a movimentos populares pelo Serviço Social.

Dessa forma, é válido dar importância sobre o debate na atuação do Serviço Social neste tema complexo e fecundo, trabalhado pela categoria mais recentemente, existindo poucas publicações. Sua produção bibliográfica no Serviço Social é marcada por diferentes concepções teóricas e políticas, mas no âmbito da categoria é considerado como um tema relativamente novo, e por outros profissionais e/ou experiências neste campo não se assinala sua produção teórica no Serviço Social como contemporânea, mas concorda-se que se adensou a partir da década de 1990, com a materialização do projeto ético-político profissional, que busca rompimento com práticas conservadoras, respeitando o pluralismo, a heterogeneidade no projeto hegemônico da profissão. 
Duriguetto e Marro (2016) discutem que a relação da profissão com as lutas e movimentos sociais das classes subalternas perpassa o processo histórico de construção do projeto ético-político profissional, constituindo um elemento essencial na ruptura do conservadorismo. Tendo a força política e organizativa de um conjunto variado de lutas, movimentos e organizações dos trabalhadores em meados da década de 1970. Essa força política incorporou necessidade e reivindicações, que foram sendo apreendidas teórica e operativa pela profissão.

Parafraseando Duriguetto e Marro (2016), importa ressaltar que a relação do Serviço Social com os conflitos sociais de classe e os segmentos subalternos organizados perpassa a profissão desde sua gênese, mas essa aproximação com as lutas e organizações de movimentos sociais que reivindicam direitos iniciou na década 1960 com o Movimento de Reconceituação latinoamericano. Pois, na gênese profissional a relação era permeada de controle e reprodução de dominação, e para apaziguamento.

Diante disso, ressaltam-se os pressupostos históricos do desenvolvimento de comunidade ${ }^{1}$, que foi introduzido por organismos norte-americanos de cooperação nos anos 1940 no país, mas em 1950, com o fim da Segunda Guerra Mundial e com o advento da chamada guerra fria (entre Estados Unidos e União Soviética), passa a ser disseminado pela Organização das Nações Unidas (ONU) de maneira sistemática. Assim, desenvolvimento de comunidade consistia numa estratégia de controle ideológico da população contra a possibilidade do comunismo. E, também em 1950, a ONU passou a investir no Serviço Social, realizando pesquisas no plano internacional sobre a profissão (MATOS, 2010).

Essas experiências de campos de estágio em Serviço Social atuando junto aos movimentos sociais, que se deram no Desenvolvimento de Comunidade (DC), foram os precursores dos trabalhos de assessoria do Serviço Social no país. Os poucos sujeitos profissionais (as equipes de Serviço Social) trabalhavam com a categoria assessoria no seu entendimento, contudo, o mais recorrente referia-se à categoria investigação/ação. Uma vez que, naquele período, não havia uma clara distinção entre o trabalho e a militância política, tais experiências deram bases ao trabalho dos profissionais com a assessoria. Conforme explicita o autor, "[...] aqui estão às origens deste tipo de assessoria que, na atualidade, passam por outras estratégias de ação, afinal somos sabedores de que, desde os anos 1990, assistimos, infelizmente, a um brutal refluxo dos movimentos sociais" (MATOS, 2010, p. 42).

\section{Assessoria como processo de mediação do Serviço Social}

Conforme Matos (2010), a assessoria possui suas imprecisões no âmbito do Serviço Social, apresentando que o início da atuação dos assistentes sociais junto aos movimentos sociais, de forma mais efetiva e incisiva, se deu por meio da criação de campos de estágio profissional em Serviço Social. E, essa relação do Serviço Social com os movimentos sociais, ratificou-se por meio da sua negação com o desenvolvimento de comunidade, negação que, na época, que

\footnotetext{
${ }^{1}$ Cabe explicitar que o Serviço Social participava do desenvolvimento de comunidade desde a sua origem brasileira, sendo impensável admitir essa iniciativa sem a histórica contribuição desta profissão. Assim, todas essas fases foram também vividas pelo Serviço Social. Até porque o Serviço Social ora identificava o desenvolvimento de comunidade como campo de trabalho, ora o identificava como um processo próprio da profissão, que se expressava pelo currículo que teve vigor nos anos de 1970 a 1982 haja vista a existência da disciplina de Serviço Social de comunidade (MATOS, 2010).
}

Temporalis, Brasília (DF), ano 20, n. 39, p. 191-208, jan./jun. 2020. | ISSN 2238-1856 
compreendeu o desenvolvimento de comunidade expressava o anverso do que buscava o Serviço Social.

Antecedente a pedagogia emancipatória, as atividades das Comunidades Eclesiais de Bases (CEBs), na década de 1970, culminaram com a crise profissional pela negação das bases conservadoras do Serviço Social, isso caracterizou o vínculo profissional junto às classes subalternas e sua perspectiva histórica, e à sua luta pela construção de uma sociedade alternativa ao capitalismo.

Tanto que foram os elementos constitutivos da pedagogia emancipatória resultado das experiências das Comunidades Eclesiais de Base (CEBs)², por meio de práticas cotidianas com as camadas populares, as quais politizavam, encorajavam à auto-organização, promoviam formações políticas, por debates críticos face às contradições sociais presentes na década de 1970, consequentemente, construíam o próprio processo de luta, em busca de melhores condições de vida e de contestação à ordem estabelecida.

Segundo Machado (2012), o Serviço Social dialoga com a área da educação popular "[...] não é de hoje" (MACHADO, 2012, p. 152). Para tanto, a autora destaca as produções de Netto (2002) e Faleiros (2005), que abordam as aproximações do Serviço Social com as ideias de Paulo Freire na América Latina durante o Movimento de Reconceituação da profissão. Aqui, conforme a autora, explica que "[...] os assistentes sociais começam a compreender que a erosão do Serviço Social tradicional passa pela ruptura com as amarras imperialistas do sistema capitalista" (MACHADO, 2012, p. 152).

Mas, tomar a perspectiva Freireana por paradigma crítico incorre de cometerem-se equívocos, em que Netto (2002), citado por Machado (2012), reitera que, exatamente naquele período de reconceituação da profissão, houve a presença de um ecletismo teórico em uma série de elaborações reconceitualizadas da América Latina, em que se fundamentavam no livro Pedagogia do oprimido, de Paulo Freire. Mas, apesar destes equívocos teóricos, reconhecem que só "[...] a partir de então criaram-se as bases, antes inexistentes, para pensar-se a profissão sob a lente de correntes marxistas" (NETTO, 2002, p. 149).

Com isso, “[...] podemos dizer que a articulação entre as áreas de Serviço Social e educação popular surge aproximadamente no início da década de 1970. Apesar disso, atualmente a educação popular não está muito presente nos debates acadêmicos da área do Serviço Social" (MACHADO, 2012, p. 154).

Segundo Machado (2012, p. 154), "[...] mas isso não significa que não haja assistentes sociais atuando com a educação popular e/ou debatendo-a em outras áreas, como saúde e educação por exemplo". Nesse sentido, destaca-se a compreensão que:

[...] é muito importante ocupar esses espaços coletivos, especialmente a partir da conjuntura neoliberal, quando o bloco do poder passa a difundir e empreender o trabalho comunitário sob sua direção, tendo no voluntariado um especial protagonista. Algo que "representa uma ofensiva ideológica na construção e/ou consolidação da

\footnotetext{
${ }^{2}$ Abreu (2002, p. 133 apud DURIGUETTO; BALDI, 2012, p. 196) aborda que “[...] as experiências das CEBs revelam-se espaços importantes de 'politização das relações sociais e de intervenção dessas classes no movimento histórico na perspectiva de sua emancipação', processo estes entendidos como principais vetores na constituição de uma pedagogia emancipatória".
}

Temporalis, Brasília (DF), ano 20, n. 39, p. 191-208, jan./jun. 2020. | ISSN 2238-1856 
hegemonia das classes dominantes em um contexto econômico adverso". Sobretudo, porque a perspectiva da luta por direitos, estimulada tanto pela educação popular como pelo Serviço Social, passa a ser substituída pela perspectiva da refilantropização da questão social. Diante disso, [...] se faz necessário reassumir o trabalho de base, de educação, mobilização e organização popular, que parece ter sido submerso do debate teórico-profissional ante o refluxo dos movimentos sociais e dos processos maciços de organização sindical, mas não do trabalho de campo (IAMAMOTO, 2002 apud MACHADO, 2012, p. 154).

A discussão da assessoria, Matos (2010) revela que a assessoria tem poucas recorrências sobre esse trabalho no âmbito do Serviço Social. A precursora é Balbina Ottoni Vieira (1981), que discute nos anos de 1980 sobre assessoria no seu livro acerca do viés de supervisão, o qual continha pressupostos do estrutural funcionalismo, e tratava da importância da assessoria para os assistentes sociais. Outra abordagem refere-se à experiência vivenciada por vários cursos de Serviço Social, como campos próprios de estágio junto aos movimentos sociais, já supracitado. Para tanto, explicita-se que tais trabalhos na época ainda não tratavam da assessoria, porém apresentavam-se na relação entre exercício profissional e prática política, as quais foram os precursores das atividades de assessoria atuais que os assistentes sociais desenvolvem no campo das políticas sociais.

Matos (2010) aborda que a assessoria é entendida como uma estratégia de atuação que visa à superação da tricotomia de intervenção do Serviço Social: caso, grupo e comunidade. Atualmente, assessoria no Serviço Social é apontada como uma prática rica para a atuação profissional, contudo, as incompreensões do que seja a prática de assessoria, é ressaltada em estudos, e nas análises das entrevistas com assistentes sociais que se julgam assessores, os quais não tem ideia do que trata de fato em termos âmbitos das competências, e de outras prerrogativas colocadas aos profissionais. Aponta que poucos desses estudos tratam-se de atuações em assessorias.

No Serviço Social, o tema assessoria/consultoria surge em meados dos anos de 1970 por meio de algumas produções acerca da temática, constituindo-se um tema lateralizado na profissão, o qual evidencia-se na "busca de uma nova possibilidade de atuação profissional, para além das ações profissionais classicamente desenvolvidas pelo Serviço Social" [considerando-a por meio de uma] "(intervenção junto aos usuários dos serviços sociais e políticas sociais públicas ou privadas)" (MATOS, 2010, p. 4).

Segundo Matos (2010, p. 4), a compreensão de assessoria é controversa, pois, ora é entendida como supervisão profissional, noutra como trabalho interventivo junto a comunidades ou movimentos sociais, até mesmo é entendida como militância política. $\mathrm{E}$, isto clarifica-se que não se trata de "ser uma mera questão epistemológica, entendemos como importante a desvelação do que estamos, na categoria profissional, chamando de assessoria/consultoria" (MATOS, 2010, p. 4).

Sobre isso, o autor chama atenção de que de maneira pontuais, é importante se ter a clareza do que é a prática, no âmbito da atuação, não para supervalorizá-la, mas para não incorremos em práticas sem clara distinção, e por esponanteísmos. 


\section{O LUGAR DA INTERVENÇÃO E O MOVIMENTO INSURGENTE FRENTE DOS MORADORES PREJUDICADOS DA BACIA DO UNA (FMPBU)}

O significado da palavra insurgência faz alusão à rebeldia; que se volta contra um poder estabelecido; que possui uma opinião contrária a algo ou alguém. Nessa direção, sinaliza-se a significação de cidadania insurgente que na perspectiva de Holston (2013) expressa desejos e demandas por direitos à cidade.

O autor reitera que a cidadania brasileira se caracteriza pela sobrevivência de seu regime de privilégios legalizados e desigualdades legitimadas, provindas dos governos colonial, imperial e republicano, prosperando sob a monarquia, a ditadura e a democracia.

Assim, Holston (2013) destaca que os mais conturbados regimes de cidadania desigual podem ser desfeitos por movimentos de uma cidadania insurgente, em que os movimentos vindos das periferias urbanas fizeram surgir na esfera pública novos atores políticos que, a partir da linguagem dos direitos, expandiram a cidadania democrática alicerçada em princípios igualitários, desestabilizando o regime diferenciado, sem substituí-lo, fenômeno que sinaliza a progressiva legitimação do "[...] conceito insurgente de direitos gerais fundamentados na constituição ou em texto" (HOLSTON, 2013, p. 329).

Os processos políticos e econômicos do modo de produção da sociedade capitalista configuram o cenário de lutas sociais na cidade de Belém, que representa a resistência histórica dos sujeitos sociais diante de um cenário desigual, marcado pela agudização da questão urbana em decorrência de uma lógica mercadológica que predomina mais que as necessidades humanas (DIAS; SANTOS, 2017).

No Brasil, as cidades se modernizaram por meio de uma urbanização desigual, do ponto de vista regional e do ponto de vista de suas condições estruturais. Aonde a cidade obteve maior investimento do Estado em suas infraestruturas, ali ela se urbanizou mais rapidamente, alargando e ampliando simultaneamente os vetores geradores de desigualdades e segregação social (CRUZ, 2012, p. 72).

Essas determinações sócio-históricas expressam-se na consolidação das periferias, e com tudo que envolvem processos de ocupação ilegal de terras, conflitos em torno da sua posse, novas formas de organização política, construção e melhoramento das moradias fazendo, assim, emergir novos atores políticos e uma nova concepção de cidadania que questiona regimes de privilégios.

Em contrapartida, “[...] a urbanização assumiu características diferentes neste século XXI, uma vez que o seu processo encontra-se em fase de consolidação, buscando tornar-se modelo de civilidade para todas as cidades do planeta, no contexto do capitalismo globalizado, e, assim constitui-se em sistemas citadinos" (CRUZ, 2012, p. 70).

A globalização aprofunda e diversifica a desigualdade numa sociedade histórico e tradicionalmente desigual. Para os países capitalistas centrais, a globalização significou a quebra do contrato, e para os países periféricos significou uma nova relação de dominação e exploração. Sinaliza que o sucesso da estratégia de formar formuladores de políticas para os países periféricos provêm do Banco Internacional para a Reconstrução e Desenvolvimento (BID) e Organização para Cooperação e Desenvolvimento Econômico (OCDE) são algumas das entidades que se organizam para essa tarefa de 'capacitybuilding' (MARICATO, 2015, p. 74). 
Como consequência desse processo, "[...] forja-se um Estado capaz de, ao mesmo tempo, hegemonizar os interesses da burguesia e também incorporar algumas demandas da classe trabalhadora, compondo um cenário social propício para o desenvolvimento capitalista" (FARAGE, 2014, p. 247).

Neste entremeio, a lógica orgânica da cidade urbana reflete o movimento dialético da cidade na perspectiva em que, segundo Harvey (2013), o direito à cidade não é um direito abstrato, mas sim um direito inerente às nossas práticas diárias, quer estejamos cientes disso ou não.

O neoliberalismo transformou as regras do jogo político. A governança substituiu o governo; os direitos e as liberdades têm prioridade sobre a democracia; a lei as práticas públicas-privadas, feitas sem transparência, substituíram as instituições democráticas; a anarquia do mercado e do empreendedorismo competitivo substituíram as capacidades deliberativas baseadas em solidariedades sociais. Culturas oposicionistas tiveram, de desafiar a hegemonia da ordem existente (HARVEY, 2013, p. 32).

Dentro desse cenário projetado pela sociedade capitalista contraditória e desigual, Gohn (2013, p. 16) destaca que nesse novo milênio os movimentos sociais estão retomando a cena e à mídia, em que neles apresenta a questão da autonomia que ao contrário do que existia nos anos de 1980, situando que “[...] ter autonomia não é ser contra tudo e todos, estarem isolado ou de costa para o Estado, atuando à margem do instituído; ter autonomia é fundamental, ter projetos e pensar os interesses dos grupos envolvidos com autodeterminação" (GOHN, 2013, p. 16).

É ter a crítica, mas também a proposta de resolução para o conflito que está envolvido; é ser flexível para incorporar os que ainda não participam, mas têm o desejo de participar, de mudar as coisas e os acontecimentos da forma como estão; é tentar sempre dar universalidade às demandas particulares, fazer política vencendo os desafios dos localismos; ter autonomia é priorizar a cidadania: construindo-a onde não existe, resgatando-a onde foi corrompida (GOHN, 2013, p. 16).

Nessa direção, a comunidade é tratada como um sujeito ativo, e não como coadjuvante de programas definidos de cima para baixo. A participação passa a ser concebida como uma intervenção social periódica e planejada, ao longo de todo circuito de formulação e implementação de uma política pública (GOHN, 2013).

É neste quadro geral que se apresentam as novas roupagens dos movimentos e lutas sociais, no Brasil do século XXI, e que se materializam no cotidiano da vida nas grandes e médias cidades urbanas, que se expressam pontualmente conforme o processo conjuntural que os envolvem e os impulsionam.

Este quadro instaura as agudizações dos movimentos sociais urbanos em Belém que estão se mobilizando e se organizando, por meio de denúncias dos impactos gerados pelos projetos de intervenção urbanística, em que perpassam reivindicações por melhoria das condições de moradia, pela regulamentação fundiária e pelo fim dos alagamentos (DIAS; SANTOS, 2017). É por meio destas implicações que os segmentos sociais usam estratégias de lutas, denúncias, marchas, mobilizações, passeatas, ocupações, negociações, distúrbios à ordem, e desobediência da mesma etc., como forma de resistência e avanço na garantia do direito à cidade em sua totalidade. 
A estruturação das grandes cidades é vista como estratégia de divulgação da Amazônia e a cidade como o lugar de gestão de serviços com o investimento de grandes projetos urbanos, com aporte financeiro do Banco Interamericano de Desenvolvimento (BID) nas cidades capitais, como no caso de Belém (CRUZ, 2012).

Frisa-se que essa lógica de apropriação do capital tem se instalado na Região Metropolitana de Belém, por meio de programas de infraestrutura urbana33, voltada para preparar a logística de suas cidades, criando condições para circulação da produção extraída e tornando mais atrativa para novos serviços (CRUZ; MARINHO, 2015).

Assim, o processo orgânico dialético que permeiam as relações política, econômica e social da cidade de Belém, se agudizam e se materializaram incessantemente por intermédio de Grandes Projetos e Programas de Intervenções Urbanísticas alocados pelo Estado Capitalista.

Este é o atual contexto que gira em torno das reivindicações e lutas sociais em Belém, mas com a peculiaridade de estarem alocados em áreas que compreendem as Bacias Hidrográficas ${ }^{4}$, sendo este um ponto importante a se sinalizar, pois é o que materializa a identidade dos sujeitos sociais intitulados de Prejudicados 5 , que, segundo Dias e Santos (2017, p. 67), “[...] tais sujeitos estão organizados em Frente e Comitê".

O segmento social urbano Frente dos Moradores Prejudicados da Bacia do Una (FMPBU) tem sua natureza no ano de 2013, mas desde 2008 vem denunciando as irregularidades por meio de uma ação civil pública ambiental, que ainda tramita no Ministério Público Federal. De forma espontânea, luta pelo direito de cidadania legitimada na legalidade, essas vem proveniente da decorrência dos prejuízos materiais e morais causados pela conclusão e não manutenção do Projeto Una.

Desse modo, suas reivindicações se direcionam para a manutenção dos canais, pelo fim dos alagamentos, e é composto por moradores da Bacia do Una, sendo seus instrumentos de luta a denúncia ação civil pública ambiental no Ministério Público, com apoio de entidades ${ }^{6}$ que atendem os direitos humanos, blog e panfletagem (DIAS; SANTOS, 2017).

\footnotetext{
3 Em Belém, os programas de infraestrutura que se possuem uma maior intervenção urbanística são o Programa de Macrodrenagem da Bacia Hidrográfica do Una (1980-2004), o Programa de Recuperação da Baixada do Tucunduba (1990 até os dias atuais), e o Programa de Macrodrenagem da Bacia Hidrográfica da Estrada Nova (2009 até os dias atuais).

${ }^{4} \mathrm{O}$ município de Belém possui 14 Bacias Hidrográficas. A maior parte da área continental do município encontra-se em cotas inferiores a 4 (quatro) metros, estando, portanto, diretamente sob influência dessas bacias, o que por, conseguinte, Ihes impõem uma condição de terrenos alagados ou sujeitos a inundações (permanente ou de maneira intermitente) (BELÉM, 2019).

${ }^{5}$ Este termo aparece com frequência para identificar sujeitos sociais como segmentos organizados que por algum motivo não foram beneficiados ou atendidos pelos programas e projetos urbanísticos nas áreas que sofreram intervenções urbanísticas em Belém.

${ }^{6}$ As articulações que permeiam este segmento social, na luta pelo direito à cidade, decorrem de relações sociais com entidades governamentais e não governamentais, como por exemplo, Sociedade Paraense de Defesa dos Direitos Humanos (SPDDH), a União Nacional por Moradia Popular (UNMP), a Conferência Nacional dos Bispos do Brasil (CNBB), a Comissão de Justiça e Paz da Arquidiocese de Belém, as Comunidades Eclesiais de Base Arquidiocesanas de Belém, a Ordem dos Advogados do Brasil (OAB), o Programa de Apoio à Reforma Urbana (PARU/UFPA), o Laboratório de Pesquisa e Práticas Sociais na Amazônia (LABPSAM), o Comitê Popular Urbano (CPU), a Federação de Órgãos para Assistência Social e Educacional na Amazônia (FASE) (CRUZ; SANTOS, 2017).
}

Temporalis, Brasília (DF), ano 20, n. 39, p. 191-208, jan./jun. 2020. | ISSN 2238-1856 
Nessas áreas há dificuldade de aglutinação das lutas, seja pelos prejuízos causados por projetos de intervenção urbanística ou outras reivindicações como transporte, saneamento e regularização fundiária. Somente a Bacia do Una abrange vinte (20) bairros da cidade e percebe-se a dificuldade de organização da população prejudicada pelo problema do alagamento e outras reivindicações. No entanto, o cenário de lutas em Belém demonstra a resistência por parte de tais sujeitos ao atual cenário, passividade, diante da violação cotidiana dos direitos humanos (DIAS; SANTOS, 2017, p. 10).

Portanto, nessa direção, sinaliza-se que "[...] o processo é estimulado pelo Estado onde o campo da experimentação ocorre na esfera pública - recorte do público e o privado não estatal, em que o conflito é minimizado" (GOHN, 2013, p. 29).

\section{AS DEMANDAS E O PROCESSO DE INTERVENÇÃO: O SERVIÇO SOCIAL NUMA RELAÇÃO DIALÉTICA COM MOVIMENTO INSURGENTE FMPBU}

Refletir sobre a prática de assessoria do Serviço Social desenvolvida pelo Programa de Apoio à Reforma Urbana (PARU) junto aos movimentos sociais insurgentes, especificamente a Frente dos Moradores Prejudicados da Bacia Hidrográfica do Una, em Belém, nos remete a analisar como as demandas se dão na assessoria, uma vez que essa se constitui como uma relação de trocas de saberes entre academia e o conhecimento popular das situações vivenciadas pelos sujeitos no cotidiano da cidade, dada as problemáticas do direito à cidade e direito à moradia.

Assim, o processo de intervenção tem sido realizado desde os anos de 1992 pelo PARU, definido como Programa de Ensino, Pesquisa e Extensão, iniciando trabalhos de assessoria aos movimentos sociais e, posteriormente, estende-se aos órgãos governamentais e nãogovernamentais, como objetivo de contribuir para avanços na questão da discussão sobre o direito à cidade e a moradia digna. Nessa direção, se constitui como campo de estágio profissional para alunos da Faculdade de Serviço Social (SILVA, 2016).

A ampliação possibilitou engajamento dos discentes como bolsista, estagiários desses órgãos, deu origem à articulação do ensino-extensão com a pesquisa, uma vez que através da inserção dos sujeitos foi possível a elaboração de Trabalhos de Conclusão de Curso, na graduação e dissertações de mestrado na Pós-Graduação. Tais processos criaram condições de organização e consolidação do programa enquanto força como assessoria ao movimento popular urbano em Belém (SÁ; CRUZ; COSTA, 2005. p. 47).

Esse processo de formação, conscientização e politização se dá pela relação dialética que o Serviço Social estabelece com os segmentos sociais, sendo uma mediação diferenciada que tem viés voltado para a transformação social dos sujeitos, ou seja, a materialização do trabalho interventivo da assessoria do Serviço Social aos movimentos sociais, apresentando-se nas suas múltiplas dimensões do fazer profissional técnico-operativo, teórico-metodológico e éticopolítico. Essa relação do processo interventivo do Serviço Social com o processo de mobilização e organização popular, segundo Duriguetto (2014), é explicitada na Lei de Regulamenta da Profissão no. 8.662/93, em seu art. $4^{\circ}$, parágrafo IX, e reafirmada no Código de Ética Profissional de 1993, "[....] não são apenas dimensões normativas, mas orientações tático-estratégicas e éticopolíticas" (DURIGUETTO, 2014, p. 188).

A assessoria aos movimentos sociais tem como objetivo a formação política dos sujeitos, dentro de uma relação pedagógica que se desenvolve na perspectiva de um processo de organização,

Temporalis, Brasília (DF), ano 20, n. 39, p. 191-208, jan./jun. 2020. | ISSN 2238-1856 
e de fortalecimento dos sujeitos, sendo essa a dimensão ideopolitica própria da direção social da profissão. Esta é a direção ideopolítica no campo da intervenção profissional da assessoria junto aos processos de organização e mobilização popular que significa analisar como o assistente social pode atuar na direção da promoção e fortalecimento das organizações e lutas coletivas, que estão imbricados na direção do Projeto Ético-Político Profissional (DURIGUETTO, 2014).

As atividades desenvolvidas por intermédio do Programa de Extensão PARU efetiva a assessoria do Serviço Social dentro e fora da academia, para além dos muros da universidade, por meio de ações que revelam não apenas instrumento didático-pedagógico, mas como também instrumento de luta, que são materializados em diversas ações de extensão e assessoria como: reuniões, oficinas, seminários, capacitações, entre outros, possibilitando, assim, o mapeamento de expressões da "questão social".

Reitera-se, portanto, que a experiência do processo de assessoria do Serviço Social a movimentos coletivos, como por exemplo, a FMPBU, contribui com o fortalecimento dos movimentos sociais urbanos na luta pela defesa de seus direitos, os quais envolvem diversos atores públicos e sociais na trama da formulação de políticas públicas, por meio de práticas inovadoras de extensão universitária, de inclusão da sociedade civil e do Estado, nos processos de investigação, intervenção e proposição de políticas públicas de desenvolvimento local e regional.

O PARU sinaliza, por meio de experiência acumulada, o avanço das práticas extensionistas direcionadas por intermédio da manutenção de práticas investigativas e interventivas junto aos movimentos sociais, órgãos públicos e comunidades locais, no debate junto às demandas sociais com utilização de metodologia participativa na elaboração do planejamento e implementação de políticas públicas.

Um dos maiores desafios para os setores organizados e consciente de dimensão e da complexidade das coisas objetivas da sociedade capitalista na atualidade é a criação e sustentação de mecanismos de resistência e de luta (LOPES, 2012). Nesse contexto, "[...] o direito à cidade não é apenas um direito condicionado de acesso aquilo que já existe, mas sim um direito ativo de fazer a cidade diferente [...] de acordo com nossas necessidades" (HARVEY, 2013, p. 33).

Somando a isto desenvolve práticas que envolvem bolsistas e parceiros institucionais e sociais, que possibilita uma formação baseada em saberes constituídos com princípios democráticos e de cidadania. Também esse processo possibilita a produção de saberes que se revelam em pesquisas e sistematização de conhecimento na concretização de textos, monografias e dissertações que passam a contribuir com o processo de conhecimento da realidade local da Amazônia.

Pode-se explicitar que a prática da assessoria do Serviço Social desenvolvida pelo PARU a movimentos sociais urbanos em Belém, no âmbito da formação profissional, permite evidenciar o processo da formação política que expressa significante grau de importância, no campo do Serviço Social, na direção ideopolítica da profissão, como também com movimentos sociais, estreitando laços no processo da formação, conscientização e politização dos sujeitos envolvidos. 
Assim, por meio de uma intervenção diferenciada, proporciona uma relação pedagógica que está intimamente ligada às competências do profissional de prestar assessoria e apoio aos movimentos, e se reafirmando no Código de Ética (1993), sendo orientações tático-estratégica e ético-política (DURIGUETTO, 2014).

Portanto, exercita-se essa relação pedagógica na dimensão interventiva, devido os vínculos contraditórios que se estabelecem ao projeto societário na dimensão ideopolítica para o processo de organização e mobilização popular, por meio de uma intervenção que possa promover e fortalecer as organizações e lutas coletivas da classe trabalhadora, sendo essa uma direção de caráter político (DURIGUETTO, 2014). Destacando-se a significância do trabalho de base, sendo o lócus necessário para tal relação - Serviço Social e movimento social.

O processo técnico e metodológico compreende nos parâmetros para atuação, pois tem que se ter domínio do instrumental de trabalho, que depende da realidade da demanda que se apresenta dentro de uma determinada conjuntura. Reitera-se que o trabalho social exercido pelo assistente social na assessoria a movimentos sociais urbanos pressupõe-se que o profissional esteja em constante conhecimento teórico-metodológico, para compreensão da realidade social e o reconhecimento das demandas possibilitando ação profissional (CONSELHO FEDERAL DE SERVIÇO SOCIAL, 2012).

A questão do processo da tutela implica nos limites em que as lideranças dos movimentos não podem ficar dependentes da assessoria. Eles têm que ter autonomia para serem os protagonistas de suas lutas. Ver-se a importância de compreender esse processo de estar junto articulando e desenvolvendo estratégias com os sujeitos coletivos.

Essa relação dialética do Serviço Social e os segmentos organizados é uma mediação diferenciada voltada para transformação social dos sujeitos fortalecendo na discussão da política, no alcance de conhecimento para fins de instrumentalização para as lutas que enfrentam cotidianamente diante do Estado e suas implicações.

Nesse jogo contraditório e desigual, orientada pela lógica neoliberal, que se agudizam o modo de produção capitalista que pressionam os sujeitos-históricos a se (re)organizarem coletivamente, ou até mesmo individualmente, circunscritos na problemática da questão urbana que envolve inúmeras expressões da "questão social”, como a habitação; o uso do solo; serviços e equipamentos coletivos; entre outras expressões.

\section{CONSIDERAÇÕES FINAIS}

A articulação com os movimentos sociais insurgentes, pela via da extensão universitária, evidencia, principalmente, o papel da Universidade na constituição de uma nova cultura, de novas visões de mundo, que não são apenas transmissão de conhecimentos científicos. Nesse sentido, a importância desse trabalho é reafirmada por esse direcionamento, no qual, por meio da assessoria do Serviço Social desenvolvida pelo Programa de Apoio à Reforma Urbana, e a formação sociopolítica aos movimentos sociais que lutam pelo direito à cidade, objetiva-se a maior participação dos sujeitos nas arenas participativas. 
A prática de assessoria do Serviço Social deve ser permeada pela efetivação da transformação social, voltada numa perspectiva de consolidação da democracia. Diante disso, acredita-se que a participação, seja fundamentada por princípios basilares de defesa da democracia, dos direitos humanos para a efetivação de uma participação qualificada, crítica, politizada.

Sendo assim, a proposição visa concomitante promover ações extensionista que estabeleçam articulação entre Universidade Pública (UFPA) junto aos Movimentos Sociais Urbanos e Populares, sendo pertinente integrar alunos, professores e sujeitos políticos, órgãos estatais, na contribuição de experiências, e trocas, por intermédio de uma formação política e qualificada, com vistas à participação desses sujeitos (Estados e Movimentos Sociais) na cena pública.

Por meio dessa experiência, de capacitação e assessoramento, aos movimentos sociais insurgentes tem-se constituído um instrumento indispensável para autonomia e visão crítica da realidade, da qual estão inseridos, por intermédio do PARU, via pesquisa e ações extensionistas, que discutem estratégias de combate aos alagamentos ocasionados por grandes projetos de macrodrenagem.

O processo de assessoria à Frente dos Moradores Prejudicados da Bacia do Una (FMPBU) se deu, principalmente, em audiências públicas, objetivando dar continuidade nas discussões sobre a judicialização de uma Ação Civil Pública de caráter indenizatório em favor da população de Belém. Esse enfrentamento, de luta cotidiana do movimento FMPBU, correlaciona-se com a práxis da assessoria do Serviço Social, na perspectiva da formação sociopolítica e transformação social dos sujeitos envolvidos, por intermédio de trocas de saberes.

Isto tudo infere que a relação de assessoria do Serviço Social desenvolvida pelo PARU junto aos movimentos sociais insurgentes está envolvida intimamente com processos sócio-históricos, os quais se explicitam no processo da tutela, que tem uma linha tênue entre dependência e autonomia, que implica nos limites, em que os sujeitos não devem ficar dependentes da assessoria, eles têm que ter autonomia, sendo, assim, os protagonistas de suas lutas, e, para isso, é necessária a formação política, por meio de técnicas e metodologias, com rigor ético-político e teórico-metodológico, para o alcance da materialização da formação pedagógica.

Nesse viés, a interlocução Serviço Social e movimentos sociais insurgentes é fundamental, pois abrange a dimensão interventiva imbricada em processos correlacionados em pressupostos de mediação, que agregam qualificação às lutas sociais pelo direito à cidade e à moradia digna, fomentando espaços políticos que possibilitam a autonomia e a organização dos sujeitos sociais.

\section{REFERÊNCIAS}

BELÉM (Município). Bacias Hidrográficas de Belém. Belém. @2019. Disponível em: http://www.belem.pa.gov.br/app/c2ms/v/?id=18\&conteudo=4756. Acesso em: 10 jun. 2018.

\section{CONSELHO FEDERAL DE SERVIÇO SOCIAL. (Org.). Atribuições privativas do/a assistente social} em questão. Brasília (DF), 2012. Disponível em: http://www.cfess.org.br/arquivos/atribuicoes2012-completo.pdf. Acesso em: 5 maio 2018.

CRUZ, Sandra Helena Ribeiro; SANTOS, Gizele Cristina Carvalho dos. Lutas Sociais e Grandes Projetos Urbanos em Belém: as “Frentes dos Prejudicados”. In: SEMINÁRIO INTERNACIONAL DA AMÉRICA LATINA (SIALAT), 2., 2017, Belém. Anais [...]. Belém, 2017. 
CRUZ, Sandra Helena Ribeiro; MARINHO, Taynáh de Nazaré Argolo. Vida Urbana e Participação no Contexto do PROMABEN, em Belém. Projeto de Pesquisa Universidade Federal do Pará (UFPA). Belém, 2015.

CRUZ, Sandra Helena Ribeiro. Grandes Projetos Urbanos, Segregação Social e condições de moradia em Belém e Manaus. 2012. Tese (Doutorado em Desenvolvimento Sustentável do Trópico Úmido)-Programa de Pós-Graduação em Desenvolvimento Sustentável do Trópico Úmido, Núcleo de Altos Estudos Amazônicos, Universidade Federal do Pará, Belém, 2012.

DIAS, Maurício Leal; SANTOS, Gizele Cristina Carvalho dos. Lutas Sociais pelo Direito à Cidade em Belém. In: JORNADA INTERNACIONAL DE POLÍTICAS PÚBLICAS (JOINPP), 8., 2017, São Luis. Anais [...]. São Luis, 2017.

DURIGUETTO, Maria Lúcia. Movimentos Sociais e Serviço Social no Brasil pós-anos 1990. In: ABRAMIDES, Maria Beatriz; DURIGUETTO, Maria Lúcia (Orgs.). Movimentos Sociais e Serviço Social: uma relação necessária. São Paulo: Cortez, 2014.

DURIGUETTO; Maria Lucia; BALDI, Luiz Agostinho de Paula. Serviço Social, mobilização e organização popular: uma sistematização do debate contemporâneo. Katálysis, Florianópolis: Editora da UFSC, v. 15, n. 2, jun./dez., 2012.

DURIGUETTO, Maria Lúcia; MARRO, Kátia. Serviço Social, lutas e movimentos sociais: a atualidade de um legado histórico que alimenta os caminhos de ruptura com o conservadorismo. In: SILVA, Maria Liduína de O. (Org.). Serviço Social no Brasil: história de resistência e de ruptura com o conservadorismo. São Paulo: Cortez, 2016. p. 97-115.

FALEIROS, Vicente de Paula. Reconceituação do Serviço Social no Brasil: uma questão em movimento? Revista Serviço Social \& Sociedade n. 84. p. 21-36. São Paulo: Cortez, 2005.

FARAGE, Eblin. Experiências profissionais do Serviço Social nos movimentos sociais urbanos. In: ABRAMIDES, Maria Beatriz; DURIGUETTO, Maria Lúcia. (Orgs). Movimentos Sociais e Serviço Social: uma relação necessária. São Paulo: Cortez, 2014.

GOHN, Maria da Glória. Movimentos sociais na atualidade: manifestações e categorias náuticas. In: GOHN, Maria da Glória. Movimentos sociais no início do século XXI: antigos e novos atores sociais. 6. ed. Rio de Janeiro: Vozes, 2013. p. 13-32.

HARVEY, David. A liberdade da cidade. In: MARICATO, Ermínia et al. Cidades Rebeldes: passe livre e as manifestações que tomaram as ruas do Brasil. São Paulo: Boitempo, 2013. p. 27-34.

HOLSTON, James. Cidadania insurgente: disjunções da democracia e da modernidade no Brasil. Tradução Claudio Carina; revisão técnica Luísa Valentini. 1. ed. São Paulo: Companhia das Letras, 2013.

LOPES, Josefa Batista. Resistência de classes e o PT na construção de alternativas no Brasil. In: COUTINHO, Joana A.; LOPES, Josefa B. (org.). Crise do capital, lutas sociais e políticas públicas. São Paulo: Xamã, 2012, p. 213-231. 
MACHADO, Aline Maria Batista. Serviço Social e educação popular: diálogos possíveis a partir de uma perspectiva crítica. Revista Serviço Social \& Sociedade, n. 109, p. 151-178, jan./mar. 2012.

MARICATO, Ermínia. Para entender a crise urbana. São Paulo: Expressão Popular, 2015.

MARICATO, Ermínia. É a questão urbana, estúpida!. In: MARICATO, Ermínia et al. Cidades rebeldes: passe livre e as manifestações que tomaram as ruas do Brasil. São Paulo: Boitempo, 2013. p. 19-26.

MATOS, Maurílio Castro de. Assessoria e consultoria: reflexões para o Serviço Social. In: BRAVO, Maria Inês Souza; MATOS, Maurílio Castro de. Assessoria, consultoria \& Serviço Social. São Paulo: Cortez, 2010.

MINAYO, Maria Cecília de Souza. O Desafio da Pesquisa Social. In: MINAYO, Maria Cecília de Souza. Pesquisa Social: teoria, método e criatividade. 18 ed. Petrópolis: Vozes, 2009. p. 9-29.

NETTO, José Paulo. Introdução ao Estudo do Método de Marx. São Paulo: Expressão Popular, 2011.

NETTO, José Paulo. Ditadura e Serviço Social: uma análise do Serviço Social no Brasil pós-64. 6. ed. São Paulo: Cortez, 2002.

SÁ, Maria Elvira Rocha de; CRUZ, Sandra Helena Ribeiro; COSTA, Solange Maria Gayoso. Programa de Apoio à Reforma Urbana - PARU: integrando o ensino, a extensão e a pesquisa. In: STOCKINGER, Silva da Costa (Org.). Textos de Teoria e Prática de Serviço Social: estágio profissional em Serviço Social na UFPA. v. 2. Belém: Ed. Amazônia-UFPA, 2005.

SILVA, Milcilene Magalhães da. Assessoria e Extensão Universitária: uma reflexão sobre a prática desenvolvida pelo Programa de Apoio à Reforma Urbana no período de 2014 a 2016. Trabalho de Conclusão de Curso (Graduação em Serviço Social)- Faculdade de Serviço Social, da Universidade Federal do Pará, Belém, 2016. 


\section{Roselene de Souza Portela*}

Assistente Social, Docente Adjunto I da Universidade Federal do Pará. Mestra em Planejamento do Desenvolvimento pelo NAEA/UFPA (2005), Doutora em Ciências Socioambientais pelo NAEA/UFPA (2011). Tem experiência na área de Serviço Social, com ênfase em Políticas Públicas, atuando principalmente nos seguintes temas: planejamento e gestão de cidades, desenvolvimento local/regional, habitação, organização social e participação popular, reforma urbana, meio ambiente, supervisão de estágio e estágio supervisionado, formação e trabalho profissional. Coordenou o Curso de Graduação em Serviço Social da Faculdade Metropolitana da Amazônia (FAMAZ) e o Programa de Apoio à Reforma Urbana (PARU/UFPA). Foi vice-diretora da Faculdade de Serviço Social da Universidade Federal do Pará (FASS/ICSA/UFPA), nos anos de 2017 2018. Atualmente é docente da Faculdade de Serviço Social e do Programa de Pós-Graduação em Serviço Social (PPGSS/UFPA).

\section{Sandra Helena Ribeiro Cruz*}

Graduada em Serviço Social e mestra em Planejamento do Desenvolvimento pela Universidade Federal do Pará (1994), Doutora em Ciências Socioambientais pelo Núcleo de Altos Estudos Amazônicos da UFPA (2012). É docente Associada I da Faculdade de Serviço Social da Universidade Federal do Pará. Tem experiência na área de Serviço Social, com ênfase em Política Urbana, Movimentos Sociais e Direitos Humanos atuando principalmente nos seguintes temas: política habitacional, intervenção urbanística, desenvolvimento social e urbano, movimentos sociais urbanos. Tem experiência ainda no campo dos Direitos Humanos e Sociais, especificamente na áreas da infância e adolescência e tráfico de pessoas para afins de exploração sexual.

\section{Milcilene Magalhães da Silva*}

Assistente Social formada pela Universidade Federal do Pará. conclusão 2017. Atualmente cursa Mestrado Acadêmico em Serviço Social no PPGSS/UFPA (2018-2020.) Participa na condição de voluntária do Projeto de Capacitação em Atenção a Saúde Adolescente - CASA que através da educação permanente em saúde do jovem no município de Belém e Região Metropolitana de Belém (RMB) qualificando processos formativos, ações de enfrentamento e prevenção sobre os temas ISTs e SSR relacionados à política de atenção à saúde do jovem. Atuou como assessora especial no Conselho Regional de Serviço Social $1^{\text {a }}$ região- CRESS/PA na Gestão da Diretoria Provisória 2017. Atuou também como bolsista no Programa de Apoio a Reforma Urbana no período de 2013 a 2016. Possui vínculo ao Grupo de pesquisa GPPUMA/UFPA. A área de pesquisa concentra em temas no âmbito do Serviço Social, Assessoria a Movimentos Sociais e conflitos sociais urbanos, Grandes Projetos Urbanos, lutas sociais, Extensão Universitária e Universidade e políticas públicas de habitação social em Belém/PA.

\section{Lidiane Maria Siqueira David*}

Assistente Social, graduada pela Universidade Federal do Pará (UFPA), em 2018. Atuou como Bolsista de Iniciação Cientifica (2017) do projeto Processo de Trabalho e Saúde das/os Assistentes Sociais que atuam nos Centros de Referência Especializada da Assistência Social (CREAS) e Instituto Nacional de Seguro Social (INSS) no Município de Belém-PA, também atuou como Bolsista de Extensão PIBEX (2017 - 2018) no projeto de extensão Serviço Social e a Prática da Assessoria à Movimentos Sociais Urbanos de Belém vinculado ao Programa de Apoio à Reforma Urbana (PARU) do Instituto de Ciências Sociais Aplicadas (ICSA) da Universidade Federal do Pará (UFPA). Tem experiência na Área do Desenvolvimento Urbano e Regional, com ênfase em Assessoria à Movimentos Sociais Urbanos (2017 2018).Também, faz discussões em temas: Movimentos Sociais Urbanos, Assessoria em Serviço Social e Políticas Urbanas.

\footnotetext{
* As autoras participaram/contribuíram com todo o processo de elaboração do artigo, que é fruto de duas pesquisas de Trabalho de Conclusão de Curso voltadas à temática: Assessoria e Extensão Universitária: uma reflexão sobre a prática desenvolvida pelo Programa de Apoio à Reforma Urbana no período de 2014 a 2016 (de autoria de Milcilene Magalhães da Silva), e Assessoria, Serviço Social e Movimentos Sociais Urbanos: a experiência da Frente de Defesa das Bacias de Belém no Programa de Apoio à Reforma Urbana, em 2017 (de autoria de Lidiane Maria Siqueira David), e também o artigo é resultado de três planos de trabalho executados sob a coordenação das professoras Roselene de Souza Portela e Sandra Helena Ribeiro Cruz.
} 